\title{
Interferência Potencialmente Alelopática do CAPim-Gengibre (Paspalum maritimum) EM ÁReas de Pastagens Cultivadas ${ }^{1}$
}

\author{
Potentially Allelopathic Interference of Paspalum maritimum in Cultivated Pasture Areas
}

\author{
SOUZA FILHO, A.P.S. ${ }^{2}$
}

\begin{abstract}
RESUMO - Este trabalho teve por objetivo determinar se a interferência mediada por substâncias químicas está envolvida nos mecanismos que o capim-gengibre (Paspalum maritimum) utiliza para invadir e formar estandes puros em áreas de pastagens cultivadas da região amazônica. Analisaram-se os efeitos potencialmente alelopáticos de extratos hidroalcoólicos de folhas e rizomas do capim-gengibre e do solo sob essa planta daninha sobre a germinação de sementes e o desenvolvimento da radícula das plantas daninhas malícia (Mimosa pudica) e mata-pasto (Senna obtusifolia) e das plantas forrageiras puerária (Pueraria phaseoloides) e capim-marandu (Brachiaria brizantha cv. Marandu). Os extratos das duas frações do capim-gengibre apresentaram alto potencial para inibir a germinação das sementes e o desenvolvimento da radícula de todas as plantas utilizadas como receptoras. A germinação das sementes das duas plantas daninhas foi mais intensamente inibida do que a das plantas forrageiras, para os extratos das duas frações do capim-gengibre. Para o desenvolvimento da radícula, malícia e puerária foram mais intensamente inibidas. Os efeitos inibitórios estiveram positivamente associados à concentração dos extratos, com inibições máximas verificadas na concentração de 3,0\%, em todos os extratos. O solo apresentou potencial inibitório da germinação de sementes e do desenvolvimento da radícula, em nível comparado àqueles promovidos pelos extratos nas concentrações entre 0,5\% e 1,5\%. Esses resultados confirmam a hipótese levantada neste trabalho, de que a interferência alelopática está envolvida nos mecanismos de invasão e de formação de estandes puros do capim-gengibre.
\end{abstract}

Palavras-chave: germinação, inibição, plantas daninhas, radícula, sementes.

\begin{abstract}
The objective of this work was to determine whether the interference mediated by chemical substances is involved in the Paspalum maritimum mechanisms to invade and form pure stands in areas of cultivated pastures of the Amazon Region. The potential allelopathic effects of hydroalcoholic extracts of leaves and rhizomes from $\boldsymbol{P}$. maritimum and the soil under this weed plant were analyzed for seed germination and radicle elongation of the weeds Mimosa pudica and Senna obtusifolia and the forage plants Pueraria phaseoloides and Brachiaria brizantha $c v$. Marandu. The extracts from the two fractions of the plant showed high potential to inhibit seed germination and radicle elongation of all the receiving plants. Seed germination of the two weeds were more intensely inhibited than that of the forage plants. Radicle elongation of M. pudica and P. phaseoloides were more intensely inhibited. The inhibition effects were positively associated to the concentration of the extract, with maximum inhibitions obtained at the 3.0\% concentration, for all the extracts. The soil showed inhibition potential for seed germination and radicle elongation, compared to the inhibition level promoted by the extracts at concentrations between 0.5 and 1.5\%. These results confirm the hypothesis that allelopathic interference is involved with the mechanisms of invasion and formation of pure stands of P. maritimum.
\end{abstract}

Keywords: germination, inhibition, weeds, radicle, seeds.

1 Recebido para publicação em 16.1.2006 e na forma revisada em 4.8.2006.

2 Eng-Agr., Doutor, Embrapa Amazônia Oriental, Trav. Dr. Enéas Pinheiro, S/N, 66095-100 Belém-PA, <apedro@cpatu.embrapa.br>. 


\section{INTRODUÇÃO}

Historicamente, as áreas de pastagens cultivadas da região amazônica são invadidas por comunidades de espécies de plantas daninhas extremamente agressivas e diversificadas, constituindo-se em um dos principais componentes dos custos de manutenção da atividade pecuária. Hecth (1979) relata que as comunidades de plantas daninhas, em áreas de pastagens cultivadas da Amazônia brasileira, incluem pelo menos 60 famílias e mais de 500 espécies. Levantamento realizado por Dantas \& Rodrigues (1980) permitiu a identificação de 118 espécies pertencentes às famílias Leguminosae, Compositae, Gramineae, Euphorbiaceae, Cyperaceae, Solonaceae, Malvaceae e Bignoniaceae. Estudos sobre a composição botânica de áreas de pastagens cultivadas do nordeste paraense permitiram o registro de 4.700 indivíduos, distribuídos em 17 famílias e 36 espécies de plantas daninhas (Modesto Júnior \& Mascarenhas, 2001). Essas espécies possuem biologia e padrão fitossociológico diferenciados, com algumas apresentando alta freqüência e baixa densidade e outras com alta freqüência de ocorrência e alta densidade. Determinadas espécies se caracterizam por formar estandes puros e, em alguns anos, passam a dominar completamente toda a área da pastagem (Dutra, 2001).

O capim-gengibre (Paspalum maritimum) é uma das espécies que se notabilizam pela alta capacidade de invadir as áreas de pastagens cultivadas, formando verdadeiras colônias puras, dominando a pastagem em poucos anos. Nas áreas onde essa espécie predomina, até mesmo outras plantas daninhas tendem a desaparecer. Neste trabalho, foi levantada a hipótese de que dois tipos de interferência estão envolvidos no modo como o capim-gengibre invade e domina as áreas de pastagens: alelospolia e a alelopatia. Embora esses dois tipos de interferência tenham conceitos bem definidos e diferenciados e sejam reconhecidas as dificuldades em se separar a parte da interferência atribuída a cada um, é perfeitamente possivel determinar se a alelopatia está envolvida na interferência observada.

As plantas produzem, estocam e posteriormente liberam para o ambiente um sem número de compostos químicos com finalidades específicas de defesa. Muitos desses compostos exercem papel importante na interação plantaplanta, fenômeno que Molisch, em 1937, chamou de alelopatia (Rice, 1987), envolvendo tanto os atributos deletérios como os estimulatórios (An et al., 1993), embora a literatura documente mais os efeitos deletérios. A principal conseqüência desse fenômeno é a alteração no padrão e na densidade das comunidades de plantas (Smith, 1989). O conhecimento das propriedades alelopáticas, em especial das plantas daninhas, permite o entendimento dos mecanismos de interferência que essas plantas exercem sobre aquelas de interesse agronômico e econômico, indicando, ainda, a importância do desenvolvimento de estratégia eficiente e constante para controlar as espécies de plantas daninhas com tais características.

Este trabalho teve por objetivo determinar se a interferência mediada por substâncias químicas está envolvida nos mecanismos que o capim-gengibre utiliza para invadir e formar estandes puros em áreas de pastagens cultivadas da região amazônica.

\section{MATERIAL E MÉTODOS}

Coleta de material vegetativo: a parte área (folhas + colmos), cortada a $5,0 \mathrm{~cm}$ de altura do solo, e o rizoma da planta daninha Paspalum maritimum foram coletados em área de pastagem de Brachiaria humidicola, totalmente infestada pela planta daninha. As duas frações passaram por processo de secagem em estufa com circulação de ar forçada, por 96 horas, em temperatura constante de $40^{\circ} \mathrm{C}$. Em seguida, foram triturados em moinho tipo Willey, obtendo-se $4,0 \mathrm{~kg}$ da parte aérea e $3,5 \mathrm{~kg}$ de rizoma, os quais foram acondicionados em sacos de plástico.

Obtenção e preparo do extrato bruto: processou-se a extração exaustiva, utilizandose como solvente solução hidroalcoólica composta de metanol: água, na proporção de 7:3. A concentração foi feita em rotavapor, tipo EL 131. A parte aquosa resultante foi, então, liofilizada. O extrato bruto foi preparado nas concentrações de 0,5, 1,5 e 3,0\%, utilizando o material liofilizado, tendo como eluente uma solução hidroalcoólica preparada à semelhança daquela utilizada na extração. A concentração máxima estabelecida neste trabalho está 
abaixo do limite determinado por Stowe (1979) para esse tipo de estudo, que é de $5,0 \%$.

Coleta de solo: na mesma área onde foram feitas as coletas de folhas e rizomas do capimgengibre, coletaram-se $5,0 \mathrm{~kg}$ de solo, na profundidade de $0-20 \mathrm{~cm}$, em diferentes locais da área. Posteriormente, procedeu-se à homogeneização e à secagem à sombra, em condições ambientais, e armazenou-se em sacos de papel.

Plantas receptoras: como plantas indicadoras dos efeitos potenciais alelopáticos foram escolhidas plantas representativas de área de pastagem cultivada, sendo duas plantas daninhas, malícia (Mimosa pudica) e mata-pasto (Senna obtusifolia); uma gramínea forrageira, capim-marandu (Brachiaria brizantha cv. Marandu); e uma leguminosa forrageira, puerária (Pueraria phaseoloides). As sementes das duas plantas daninhas foram coletadas em fazendas particulares localizadas no município de Castanhal, Pará. As sementes do capim-marandu e da puerária foram adquiridas no mercado local.

Desenvolvimento dos bioensaios: o bioensaio de germinação foi desenvolvido em câmaras de germinação, com temperatura controlada para $25^{\circ} \mathrm{C}$ constante e fotoperíodo de 12 horas, à exceção do capim-marandu, para o qual foram utilizadas temperaturas diurnas de $30^{\circ} \mathrm{C}$ e noturnas de $15^{\circ} \mathrm{C}$. A germinação foi monitorada em períodos de 10 dias para as espécies puerária, malícia e mata-pasto e 20 dias para o capim-marandu, com contagens diárias e eliminação das sementes germinadas. Cada placa de Petri, de $11 \mathrm{~cm}$ de diâmetro, forrada com uma folha de papel-filtro qualitativo, recebeu 40 sementes de cada espécie. O bioensaio de desenvolvimento da radícula foi conduzido nas mesmas condições daquele de germinação, à exceção do fotoperíodo, que foi de 24 horas. Para cada placa de Petri de $11 \mathrm{~cm}$ de diâmetro, foram colocadas três sementes pré-germinadas, aproximadamente com três dias de germinadas. Considerando a ausência de efeitos do potencial osmótico em bioensaios de alelopatia, com concentração máxima de 5,0\% (Souza Filho \& Alves, 2000), para todos os bioensaios, o tratamento testemunha constou de água destilada.
No bioensaios em que foram avaliados os efeitos do solo sobre a germinação das sementes e o desenvolvimento da radícula, os procedimentos foram os mesmos descritos anteriormente, estando a diferença no tratamento testemunha onde se usou areia lavada de fundo de rio, sendo utilizados $40 \mathrm{~g}$ de solo por placa de gerbox de $11 \times 11 \times 4 \mathrm{~cm}$.

Delineamento experimental e análise estatística: o delineamento experimental para todos os bioensaios envolvendo os efeitos dos extratos hidroalcoólicos foi inteiramente casualizado, com quatro repetições, em modelo hierárquico, com dois fatores: concentração e plantas receptoras. Nos bioensaios em que foram avaliados os efeitos do solo, o delineamento foi inteiramente casualizado com cinco repetições. Procedeu-se à análise de variância pelo teste $\mathrm{F}$, sendo as médias comparadas pelo teste de Tukey (5\%). Os dados foram analisados pelo programa computacional SAS (Sas, 1989).

\section{RESULTADOS E DISCUSSÃO}

\section{Efeitos sobre a germinação}

Folhas e rizoma do capim-gengibre efetivaram inibições significativas $(p<0,05)$ sobre a germinação das sementes de todas as espécies receptoras (Tabela 1). A magnitude das inibições esteve associada positivamente à concentração do extrato e à espécie receptora. Independentemente da fonte do extrato (folhas ou rizoma) e da espécie de planta receptora, a concentração de $3,0 \%$ foi a que promoveu as inibições de maior magnitude, sendo da ordem de 90,0, 77,0, 28,0 e 25,0\% para o extrato de folhas sobre a germinação das sementes de malícia, mata-pasto, puerária e capim-marandu e de 53,0, 60,0, 31,0 e 30,0\% as atribuídas ao extrato de rizomas sobre a germinação das sementes de malícia, matapasto, puerária e capim-marandu, respectivamente. Para concentração de $0,5 \%$ não foram verificadas inibições significativas $(p>0,05)$ sobre a germinação das sementes de puerária, capim-marandu e da planta daninha malícia, quando se analisaram os efeitos tanto do extrato de folhas como do rizoma (Tabela 1).

Comparativamente, as duas plantas daninhas tiveram a germinação de suas sementes inibidas em intensidades superiores àquelas 
observadas para a gramínea e a leguminosa forrageira, nas duas fontes de extrato testadas, com exceção das sementes de malícia na concentração de $0,5 \%$ de extrato de folhas e de 0,5 e $1,5 \%$ de extrato de rizoma. Conquanto o modelo matemático não permita comparações entre os efeitos promovidos pelas duas fontes de extrato, folhas e rizomas, os dados da Tabela 1 indicam que o extrato preparado a partir das folhas evidenciou maior potencial inibitório da germinação das sementes de todas as espécies receptoras.

\section{Efeitos sobre o desenvolvimento da radicula}

Os efeitos sobre o desenvolvimento da radícula (Tabela 2 ) foram semelhantes àqueles sobre a germinação de sementes, com variações nas intensidades das inibições em função do aumento da concentração do extrato, com as inibições mais intensas obtidas na concentração de $3,0 \%$, da ordem de 47,0\% (malícia), 25,0\% (mata-pasto), 35,0\% (puerária) e 30,0\% (capim-marandu) e de 52,0\% (malícia), 54,0\% (mata-pasto), 65,0\% (puerária) e 45,0\% (capim-marandu), efetivadas pelos extratos de folhas e rizomas, respectivamente. Embora o modelo matemático não permitisse a comparação dos efeitos das duas fontes de extratos, os dados da Tabela 2 deixam claro que, ao contrário dos efeitos observados sobre a germinação de sementes, o extrato preparado a partir do rizoma mostrou maior potencial inibitório do que aquele de folhas. As espécies receptoras apresentaram graus de respostas diferenciados aos efeitos dos extratos, com malícia sendo a espécie mais sensível aos efeitos potencialmente alelopáticos dos extratos (Tabela 2).

Tabela 1 - Efeitos potencialmente alelopáticos de extratos aquosos de folhas e rizomas de capim-gengibre sobre a germinação de sementes de diferentes espécies de plantas de áreas de pastagens cultivadas. Dados expressos em percentual de inibição em relação ao tratamento testemunha: água destilada

\begin{tabular}{|c|c|c|c|c|c|}
\hline \multirow{2}{*}{ Parte da planta } & Concentração & \multicolumn{4}{|c|}{ Planta receptora } \\
\cline { 2 - 6 } & $(\%)$ & Malícia & Mata-pasto & Puerária & Capim-marandu \\
\hline \multirow{3}{*}{ Folhas } & 0,5 & $6,0 \mathrm{Cb}$ & $26,0 \mathrm{Ca}$ & $4,0 \mathrm{Cc}$ & $6,0 \mathrm{Cc}$ \\
& 1,5 & $50,0 \mathrm{Bb}$ & $58,0 \mathrm{Ba}$ & $11,0 \mathrm{Bc}$ & $13,0 \mathrm{Bc}$ \\
& 3,0 & $90,0 \mathrm{Aa}$ & $77,0 \mathrm{Ab}$ & $28,0 \mathrm{Ac}$ & $25,0 \mathrm{Ac}$ \\
\hline \multirow{3}{*}{ Rizoma } & 0,5 & $3,0 \mathrm{Cc}$ & $17,0 \mathrm{Ca}$ & $5,0 \mathrm{Cb}$ & $6,0 \mathrm{Cb}$ \\
& 1,5 & $8,0 \mathrm{Bc}$ & $38,0 \mathrm{Ba}$ & $10,0 \mathrm{Bbc}$ & $12,0 \mathrm{Bb}$ \\
& 3,0 & $53,0 \mathrm{Ab}$ & $60,0 \mathrm{Aa}$ & $31,0 \mathrm{Ac}$ & $30,0 \mathrm{Ac}$ \\
\hline
\end{tabular}

Médias seguidas de letras iguais, maiúscula na coluna e minúscula na linha, para cada parte da planta doadora, não diferem pelo teste de Tukey $(5 \%)$.

Tabela 2 - Efeitos potencialmente alelopáticos de extratos aquosos de folhas e rizomas de capim-gengibre sobre o desenvolvimento da radícula de diferentes espécies de plantas de áreas de pastagens cultivadas. Dados expressos em percentual de inibição em relação ao tratamento testemunha: água destilada

\begin{tabular}{|c|c|c|c|c|c|}
\hline \multirow{2}{*}{ Parte da planta } & Concentração & \multicolumn{4}{|c|}{ Planta receptora } \\
\cline { 2 - 6 } & $(\%)$ & Malícia & Mata-pasto & Puerária & Capim-marandu \\
\hline \multirow{3}{*}{ Folhas } & 0,5 & $8,0 \mathrm{Ca}$ & $5,0 \mathrm{Ca}$ & $6,0 \mathrm{Ca}$ & $5,0 \mathrm{Ca}$ \\
& 1,5 & $13,0 \mathrm{Ba}$ & $13,0 \mathrm{Ba}$ & $12,0 \mathrm{Ba}$ & $14,0 \mathrm{Ba}$ \\
& 3,0 & $47,0 \mathrm{Aa}$ & $25,0 \mathrm{Ad}$ & $35,0 \mathrm{Ab}$ & $30,0 \mathrm{Ac}$ \\
\hline \multirow{3}{*}{ Rizoma } & 0,5 & $16,0 \mathrm{Cb}$ & $23,0 \mathrm{Ca}$ & $25,0 \mathrm{Ca}$ & $15,0 \mathrm{Cb}$ \\
& 1,5 & $35,0 \mathrm{Bc}$ & $38,0 \mathrm{Bb}$ & $52,0 \mathrm{Ba}$ & $30,0 \mathrm{Bd}$ \\
& 3,0 & $52,0 \mathrm{Ab}$ & $54,0 \mathrm{Ab}$ & $65 . \cdots \cdots$ \\
\hline
\end{tabular}

Médias seguidas de letras iguais, maiúscula na coluna e minúscula na linha, para cada parte da planta doadora, não diferem pelo teste de Tukey $(5 \%)$. 
Considerando a inibição mínima de 50\% como padrão satisfatório para avaliar as potencialidades alelopáticas de um extrato (Dudai et al., 1999), neste trabalho, inibições dessa ordem foram observadas sobre a germinação de sementes das espécies malícia e mata-pasto, a partir da concentração de $1,5 \%$ para extrato de folhas e na concentração de $3,0 \%$ para os extratos de rizomas, respectivamente; já para os efeitos sobre o desenvolvimento da radícula, apenas o extrato de rizomas, a partir da concentração de 1,5\% para puerária e na concentração de 3,0\% para malícia, puerária e mata-pasto, apresentou efeitos inibitórios dessa magnitude (Tabelas 1 e 2).

\section{Efeitos do solo}

Os dados da Figura 1 mostram diferenças significativas $(p<0,05)$ na germinação e no desenvolvimento da radícula entre as espécies testadas. As inibições promovidas pelo solo apresentaram diferentes magnitudes, como variações entre 10 e 33\%. Mata-pasto foi a espécie que teve a germinação inibida em maior intensidade, ficando o desenvolvimento da radícula do capim-marandu como o mais sensivel, embora não tenha diferido estatisticamente da espécie malícia. Comparando as inibições efetivadas pelo solo com aquelas promovidas pelos extratos de folhas e rizomas do capim-gengibre, observa-se que as primeiras foram equivalentes às encontradas entre as concentrações de 0,5 e 1,5\%. Essas informações indicam que os compostos químicos envolvidos nas inibições alelopáticas promovidas pelos extratos das duas frações do capim-gengibre são liberados para o ambiente pelas mais diferentes formas reconhecidas (Hallingan, 1975; Netzly \& Butler, 1986; Oleszak et al., 1992; Lovett \& Hoult, 1995), acumulando-se no solo em níveis capazes de inibir a germinação das sementes e o desenvolvimento da radícula dos diferentes componentes da pastagem, em proporções equivalentes às concentrações de 0,5 e 1,5\%.

À medida que os compostos químicos produzidos pelo capim-gengibre são liberados para o ambiente, eles impõem limitações à germinação de sementes de outras espécies, restringindo o fluxo de novo indivíduos para a área de pastagem, comprometendo assim a renovação das demais espécies de plantas.

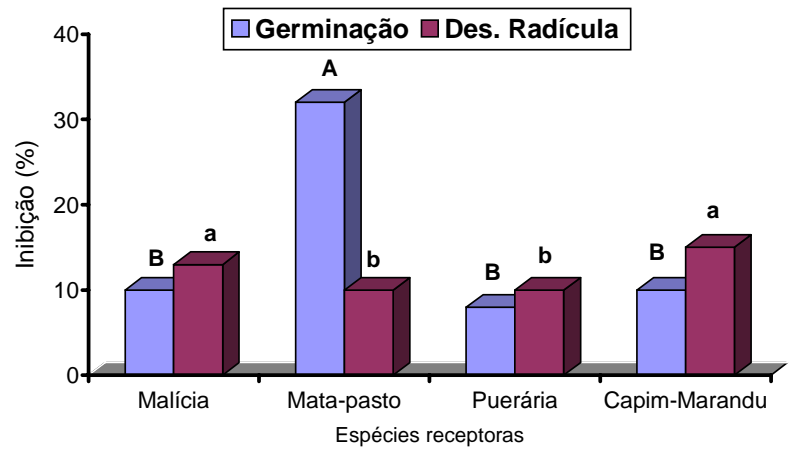

Médias seguidas de letras maiúsculas (Germinação) e minúsculas (Des. Radícula) não diferem pelo teste de Tukey (5\%).

Figura 1 - Efeitos do solo coletado em área infestada de capimgengibre sobre a germinação de sementes e o desenvolvimento da radícula de diferentes plantas de pastagens cultivadas. Dados expressos em percentual de inibição em relação ao tratamento testemunha: areia lavada.

Já as restrições ao desenvolvimento da radícula levam à diminuição da capacidade competitiva das espécies afetadas, favorecendo a proliferação do capim-gengibre. Esses resultados indicam que a velocidade e a forma com que o capim-gengibre invade e domina as áreas de pastagens cultivadas da Amazônia estão associadas, além de outros fatores relativos à alelospolia, à produção e liberação de substâncias químicas com propriedades alelopáticas para o ambiente, o que confirma a hipótese levantada neste trabalho.

A principal conseqüência desses fatores é a diminuição da produtividade e da longevidade das plantas forrageiras, bem como o aumento da infestação do capim-gengibre e, conseqüentemente, dos custos de manutenção ou de renovação da pastagem. Essa constatação aponta para a necessidade de se manter controle freqüente do capim-gengibre, evitando que ele se estabeleça nas áreas de pastagens cultivadas.

\section{LITERATURA CITADA}

AN, M.; JOHNSON, I. R.; LOVETT, J. V. Mathematical modelling of allelopathy: biological response to allelochemicals and its interpretation. J. Chem. Ecol., v. 19, p. 2379-2389, 1993.

DANTAS, M.; RODRIGUES, I. A. Plantas invasoras de pastagens cultivadas na Amazônia. Belém: Embrapa, 1980. 23 p. (Embrapa-CPATU. Boletim de Pesquisa, 1). 
DUDAI, N. et al. Essential oils as allelochemicals and their potential use as bioerbicides. J. Chem. Ecol., v. 25, n. 5, p. 1079-1089, 1999.

DUTRA, S. Análise fitossociológica de comunidades de espécies invasoras em ecossistemas de pastagens cultivadas na região nordeste paraense. 2001. $196 \mathrm{f}$. Tese (Doutorado em Ciências Biológicas) - Universidade Federal do Pará, Belém, 2001.

HALLINGAN, J. P. Toxic terpenes from Artemisis californica. Ecology, v. 56, p. 999-1003, 1975.

HECHT, S. Leguminosas espontâneas em pastagens cultivadas da Amazônia brasileira. In: TERGAS, L. E.; SANCHEZ, P. A.; SERRÃO, E. A. S. (Eds.). Produção de pastagens em solos ácidos dos trópicos. Cali: CIAT, 1979. p. 81-93.

LOVETT, J. V.; HOULT, H. C. Allelopathy and self-defense in barley. In: INDERJIT; DAKSHINI, K. M. M.;

EINHELLIG, F. A. (Eds.). Allelopathy: organisms, processes and applications. Washington: American Chemical Society, 1995. p. 170-183. (ACS. Symposium Series, 582).

MODESTO JÚNIOR, M. S.; MASCARENHAS, R. E. B. Levantamento da infestação de plantas daninhas associadas a uma pastagem cultivada de baixa produtividade no nordeste paraense. Planta Daninha, v. 19, n. 1, p. 11-21, 2001.
NETZLY, D. H.; BUTLER, L. G. Roots of sorghum exude hydrophobic droplets containing biologically active components. Crop Sci., v. 26, p. 775-778, 1986.

OLESZEK, W.; JURZYSTA, M.; GÖRKI, P. M. Alfafa saponins- The allelopathic agents. In: RIZVI, S. J. H.; RIZVI, V. (Eds.). Allelopathy. New York: Chapman \& Hall, 1992. p. 151-167.

RICE, E. L. Allelopathic effects on nitrogen cycling. In: WALLER, G. R. Allelochemical, role in agriculture and forestry. Washington: American Chemical Society, 1987. p. 7-22. (ACS. Symposium Series, 330).

SAS INSTITUTE. Statistical Analysis System. User's Guide. Version 6. 4.ed. Cary: 1989. 846 p.

SMITH, A. E. The potential allelopathic characteristics of bitter sneezeweed (Helenium amarum). Weed Sci., v. 37 , p. 665-669, 1989.

SOUZA FILHO, A. P. S.; ALVES, S. M. Potencial alelopático de plantas de acapu (Vouacapoua americana): efeitos sobre plantas daninhas de pastagens. Planta Daninha, v. 18, n. 3, p. 435-441, 2000.

STOWE, L. G. Allelopathy and its influence on the distribution of plants in an Illinois old-field. J. Ecol., v. 67, p. 1065-1068, 1979. 